Chapter 7

\title{
Potential Cell-Based Therapies for Irreversibly Damaged Salivary Glands and Atrophic Alveolar Bone
}

\author{
Yoshinori Sumita, Izumi Asahina, Simon D. Tran, \\ Hideki Agata, Minoru Inoue, Arinobu Tojo and \\ Hideaki Kagami
}

Additional information is available at the end of the chapter

http://dx.doi.org/10.5772/58913

\section{Introduction}

One of the major recent advances in medicine is the use of living cells for treatment. For example, hematopoietic stem cells (HSCs) have been transplanted to leukemic patients (bone marrow transplantation) (McGovern et al., 1956; Atkinson et al., 1959; Thomas et al., 1959). Isolated stem cells from the donor were infused into the recipient's blood stream. Those infused cells replaced the recipient's diseased HSCs. Similarly, pancreatic islets were isolated from donors and transplanted to diabetic patients (Shapiro et al., 2000). In these applications, the cells were isolated and used directly without modifications. From the 1980's, this approach has been expanded to include the use of cells that have been extensively manipulated in vitro. For example, autologous keratinocytes were isolated from skin, expanded in vitro and transplanted to the skin defects of burned patients (Gallico et al., 1984). A similar approach has been reported for the replacement of damaged cartilage at the knee joint. Cartilage cells harvested from non-load bearing site of the knee joint were cultured and transplanted to the damaged site, leading to a significant reduction of pain and increased mobility (Brittberg et al., 1994). Currently, treatments using living cells (either non-modified or modified cells) are one of the most promising fields in medicine. As for the field of dentistry, treatments using living cells have been investigated for several tissues. In particular, bone defects and damaged salivary glands have been considered as realistic targets for cell-based therapies (Kagami et al., 1998, 2014; Tran et al., 2011). This chapter will focus on the history and current status of cell therapy to those dental organs. 


\section{Cell therapy to salivary gland}

Patients with the irreversible loss of salivary gland function are seen in Sjögren's syndrome (SS) and after radiation \pm chemotherapy treatment for head and neck cancer. They usually suffer considerable morbidity and severe reduction in their quality of life because the dysfunction of the salivary glands leads to severe xerostomia (dry mouth), dysphagia, dental caries, oro-pharyngeal infections and diminished mucosal wound healing. Although the etiopathologic bases of SS and radiogenic atrophy are quite different, these conditions arise from the progressive loss of acinar cells, which are the principal site of fluid-and proteinsecretion in salivary glands. Unfortunately, there are no adequate treatments for patients with such irreversible glandular damage. Current pharmacological approaches aim to increase the secretory capacity of the surviving acinar cells but this approach is not feasible if few or no acinar cells remain in the glands. Therefore, developing alternative treatment strategies to restore acinar cells in damaged salivary glands are required.

\subsection{Experimental approaches to restore the functional salivary glands}

Recently, experimental approaches to regenerate functional acinar cells such as the use of gene therapy, tissue engineering (for developing an artificial gland), or cell-based therapy have been explored with the aim of developing novel clinical treatments (Baum \& Tran, 2006; Baum et al., 2012; Khalili et al., 2014; Sugito et al., 2004; Sumita et al., 2011; Tran et al., 2005). Gene therapy involves the transfer of genes into residual cells of atrophied glands to promote saliva secretion, and it is a promising strategy for a future clinical treatment. This approach focuses on the delivery of a water-channel protein gene to the surviving ductal epithelial cells using a recombinant adenovirus vector. In fact, promising results were recently reported from a clinical trial administering the aquaporin 1 gene for radiogenic dysfunction of salivary glands (Baum et al., 2012). An alternate strategy, tissue engineering an artificial salivary gland, is also a promising approach to the replacement of lost or damaged glands. This strategy requires both salivary epithelial stem/progenitor cells and a biodegradable scaffold that reconstructs the microenvironment of glandular tissues. We have shown that it is feasible to culture salivary epithelial cells for their eventual use in a prototype artificial salivary gland (Tran et al., 2005). However, though this strategy can generate one portion of salivary parenchymal tissue (ductal cells), it is difficult to regenerate the fully functional salivary tissues (both ductal and acinar cells). Recently, a fully functional salivary gland in adult mice has been shown possible through the orthotopic transplantation of a bioengineered salivary gland germ, which was reconstituted from epithelial and mesenchymal cells isolated from an embryonic salivary gland germ (Ogawa et al., 2013). This study provided valuable results for future tissue engineering strategies to create an artificial salivary gland in patients.

Meanwhile using another experimental strategy, we have focused on a cell-based therapy with the intention to deliver stem/progenitor cells to atrophic glands by intra-glandular or -venous injections for increasing the regenerative capacity of the damaged tissues and providing the salivary gland stem cells that can differentiate to functional acinar cells. To date, promising cell sources using this strategy have been stem/progenitor cells derived from salivary glands, 
bone marrow, umbilical cord, or adipose tissue (Khalili et al., 2012, 2014; Kojima et al., 2011; Lombaert et al., 2008; Sugito et al, 2004; Sumita et al, 2011; Xu et al, 2012). Using cells from the salivary glands, we previously demonstrated that the cultured rat salivary epithelial cells could be transplanted into atrophic glands. These cells remained in the damaged gland tissues for 4 weeks (Sugito et al., 2004). Moreover, it was shown that the spheroid culture of adult salivary gland cells could enrich the progenitor cells (salispheres) and these progenitors restored the gland morphology and functions after intra-glandular transplantation (Lombaert et al., 2008). These reports showed that the stem/progenitor cells derived from salivary glands could be considered as a promising source of cell therapy for the radiogenic dysfunction of salivary glands. Our group has also focused on bone marrow-derived cells (BMDCs), including mesenchymal stem cells (MSCs) as a cell-based strategy. We previously found that donor BMDCs migrated to salivary glands and transdifferentiated into salivary epithelial cells after their intravenous injection in human patients (Tran et al., 2011). Owing to this, their potential benefits would have been expected to regenerate the functions of atrophic glands caused by both SS and radiation therapy. It has been reported that BMDCs display the effects of paracrine, vasculogenesis, transdifferentiation or immunomodulation after transplantation in the regeneration of various tissues (Tran et al., 2011). Herein, as a prerequisite for future clinical trials, we summarize our preliminary results of studies using two different models of damage to salivary glands, which allowed to analyze the regenerative capacity of BMDCs.

\subsection{Behaviors of donor BMDCs in radiogenic dysfunction model}

Treatment for most patients with head and neck cancers includes ionizing radiation \pm chemotherapy. And, this treatment causes the irreversible damage to salivary glands, which is accompanied with a loss of fluid-secreting acinar cells and a considerable decrease of saliva secretion. To develop a cell-based therapy for this dysfunction, we firstly investigated whether non-cultured fresh BMDCs could differentiate into salivary epithelial cells and restore gland's function in head and neck irradiated mice (Sumita et al., 2011). BMDCs from male donor mice were transplanted through the tail-vein of female recipient mice post gamma-ray irradiation of 15 or 18 Gy. After 8, 16, and 24 weeks, saliva secretion was increased in mice treated by BMDCs transplantation (Figure 1).

At 24 weeks after irradiation, harvested submandibular-and parotid-glands of BMDC-treated mice had greater weights than those of non-treated mice, and possessed an increased level of tissue regenerative activity (blood vessel formation, cell proliferation, and epidermal growth factor activity), while apoptosis activity was increased in non-treated salivary glands. The expression of stem cell markers (Sca-1 or c-Kit) was increased in BMDC-treated salivary glands. Additionally, we found an increased area of acinar cells and approximately $9 \%$ of Y-chromosome positive salivary epithelial cells (derived from the donor) in BMDC-treated mice. Therefore, we drew a conclusion from this study that cell therapy using BMDCs could rescue the functional damage of irradiated salivary glands through mechanisms involving a paracrine effect as well as a direct differentiation of BMDCs into salivary epithelial cells. Likewise, several studies have shown the beneficial effects of cell-based therapies using MSCs derived from bone marrow or adipose tissues, to date (Kojima et al., 2011; Lim et al., 2013). In addition, as a proof- 


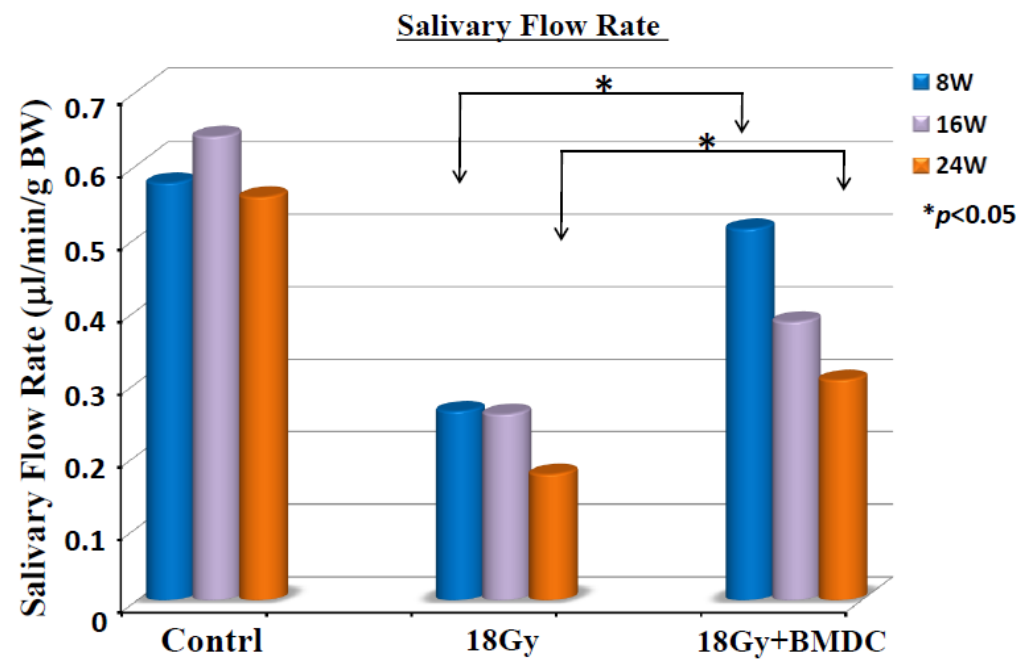

(Modified from Sumita et al., 2011)

Figure 1. Salivary flow rate recovery after BMDCs transplantation at 8, 16, 24 weeks post-irradiation. SFR were higher in BMDC-transplanted mice (18Gy+BMDC) when compared to non-transplanted ones (18Gy).

of-concept of the paracrine effect of (BMDCs) cell-based therapy, our group recently demonstrated that the injection of bone marrow cell-extracts (a bioactive lysate of BMDCs) could be advantageously used to repair the radiogenic dysfunction of salivary glands rather than BMDCs transplantation (Tran et al., 2013). Although the mechanisms of regeneration are not well understood at the present, these findings provided a promising result for future clinical trials of cell-based therapy using BMDCs or MSCs.

\subsection{Behaviors of donor BMDCs in SS model}

Sjögren's syndrome (SS) is a chronic autoimmune disease characterized by infiltrates of lymphocytes in the salivary glands. In this disease, the immune system attacks the salivary glands, particularly the acinar cells. This causes an irreversible damage that is accompanied with a progressive loss of fluid-secreting acinar cells, and leads to a considerable decrease of saliva secretion. The challenge of successful cell-based therapy for autoimmune diseases is not only to regenerate the tissue but also to prevent it from the same autoimmune attack that was responsible for its destruction at the first place (Kodama et al., 2003). Following the abovementioned concept, we initially copied a therapy proposed by Faustman and colleagues to reverse end-stage diabetes in Non-obese diabetic (NOD) mouse, but for the treatment of SSlike disease (Tran et al., 2007). NOD mice develop SS-like disease and a progressive loss of saliva secretion. This therapy had two components. First, it was an injection of complete Freund's adjuvant (CFA) to induce endogenous TNF- $\alpha$ to exterminate autoreactive T lymphocytes. The second component was the transplantation of MHC class I-matched normal 
spleen cells. As a result, our group showed that injections of CFA combined with spleen cells restored salivary function in NOD mice with SS-like disease (Tran et al., 2007). However for future clinical consideration, spleen cells are not easily obtained from patients. Therefore our group modified the Faustman's two-component therapy by using BMDCs (Khalili et al., 2010). The spleen and bone marrow are closely related organs, and both are among the first sites of hematopoiesis during gestation. We injected CFA and MHC class I-matched normal BMDCs in 7-week-old NOD mice, which had not yet developed SS. At 52 weeks posttreatment, we found that all NOD mice receiving BMDCs and CFA had a recovery of saliva secretion and were protected from SS and diabetes. Although a very small number of donor BMDCs had differentiated into salivary epithelial cells $(<0.1 \%)$, including acinar cells was observed, the size of focus score (the number of foci, infiltrated lymphocytes) was bigger in the non-treated mice (Figure 2).

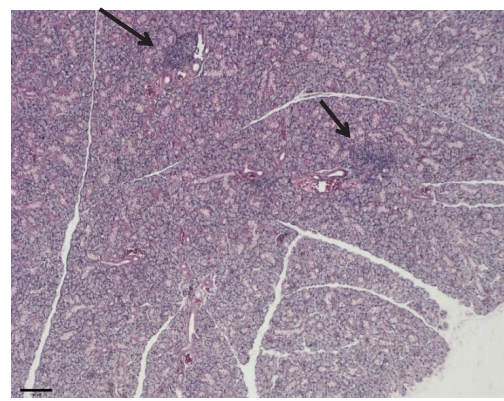

A: BMDC-treated NOD NOD

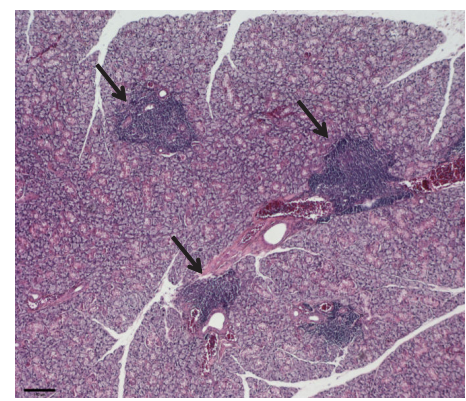

B: Non-treated

(Modified from Khalili et al., 2010)

Figure 2. Focus score change after BMDCs transplantation. The size of the focus score (black arrows) was bigger in non-treated mice (Non-treated NOD) when compared to BMDC-treated mice (BMDC-treated NOD).

This study suggests that a combined immuno and cell-based therapy can permanently prevent SS and restore the salivary function in NOD mice through mechanisms involving the paracrine and immunomodulatory effects. Moreover, we analyzed whether this BMDC-treatment would be effective in restoring salivary gland function if the treatment was given at a late phase of SS (20-week old NOD) when minimal saliva was secreted. In consequence, saliva secretion improved and was at best $50 \%$ of pre-symptomatic levels. The treatment also decreased TNF$\alpha$ and TGF- $\beta 1$ levels while increasing EGF and regulatory T cells. This study provided that the cell-based therapy using BMDCs holds a promising effect, even when given in an advanced phase of SS. Likewise, we have also confirmed MSCs derived from bone marrow display similar effectiveness (Khalili et al., 2012). The combined use of CFA and MSCs was effective in both preventing saliva secretion loss and reducing lymphocytic influx in salivary glands. Thus, cell-based therapy must be recognized as one of the promising options for future clinical trials. Recently, our group has also shown that the injection of bone marrow cell extracts (a 
bioactive lysate of BMDCs) could restore the function of damaged salivary gland in NOD mice (Misuno et al., 2014).

\section{Cell-based therapy to atrophic alveolar bone (bone tissue engineering)}

Atrophic alveolar bone is one of the major obstacles for dental implant therapy because dental implant placement requires the presence of a minimal amount of bone. For patients with severe bone atrophy, functional recovery with conventional dentures is difficult and most of the patients suffer from masticatory disturbance. A combination of autologous bone graft and dental implant installation is a realistic option for those patients with severe alveolar bone atrophy. However, the procedure is accompanied by swelling and pain of the donor site and causes morbidity. Bioartificial bone substitutes have been frequently used as an alternative, although the artificial materials cannot induce bone regeneration and the application is limited. Accordingly, tissue engineering and regenerative medicine of bone tissue is now receiving significant attention (Kagami et al., 2014).

\subsection{Scientific bases for bone tissue engineering}

Osteogenic ability is the function to generate bone after transplantation. Before the development of tissue-engineered bone, only vascular bone grafts were known to have this function. Tissue-engineered bone is designed to contain living osteogenic cells and thus possesses osteogenic function. The characteristic features of tissue-engineered bone is based on the presence of osteogenic cells.

As a source for osteogenic cells, pluripotent mesenchymal stromal cells from bone marrow aspirates have been widely used. Initially, this group of cells was defined as adherent fibroblast-like cells in bone marrow. Since the culture contains cells which can generate single cellderived colonies, those cells were referred to as colony forming units-fibroblasts (CFUs-F). Eventually, CFUs-F were proved to have high proliferating potential and even single-colony derived cells were shown capable of forming bone (Friedenstein et al., 1966; Friedenstein et al. 1970; Friedenstein et al., 1987). Subsequently, the capability of CFUs-F to differentiate to various mesenchymal tissues has been reported. Then, these cells were re-named as"mesenchymal stem cells" (MSCs) (Caplan, 1991). However, not all cells are multipotent; MSCs are also designated as "bone marrow stromal cells (BMSCs)", which is a relatively widely accepted nomenclature (Prockop, 2009). Although BMSCs can be obtained from a patient's own bone marrow aspirate, the percentage of BMSCs in total bone marrow cells is likely less than $0.01 \%$ (Pittenger et al., 1999). Accordingly, cell cultivation is required to obtain a sufficient number of cells for clinical bone tissue engineering. For example, bone marrow from a single rat can provide a sufficient number of osteogenic cells for only two or three bone-forming transplants. In contrast, after in vitro expansion of cells from the same volume of bone marrow, more than 50 bone-forming transplants are possible (Yoshikawa et al., 1996).

The quality of cells is an important factor for tissue engineering as it could affect the treatment outcome. Accordingly, BMSCs should be appropriately processed, cultured and induced into 
osteogenic cells. For this purpose, various parameters including cell separation procedures, culture media, type and origin of serum, cell seeding density, timing of passaging, the number of passages, content and concentrations of reagents for induction and the period of induction should be optimized. Similarly, scaffold material and shape should be optimized depending on the purpose. To establish a standard operating protocol for the preparation of cells for clinical bone tissue engineering, we have investigated optimal cell culture and induction procedures using human BMSCs and granular type $\beta$-tricalcium phosphate $(\beta-\mathrm{TCP})$ as a scaffold. The results showed that the passage number, seeding density and the period of induction significantly affected the osteogenic ability of BMSCs (Agata et al., 2010). In particular, human BMSCs lose their in vivo bone forming ability very rapidly after passaging and no bone formation was observed with cells after the fourth cell passage (Fig. 3) (Agata et al., 2010). The results of those basic studies should be considered in the establishment of an optimal cell culture/induction protocol.
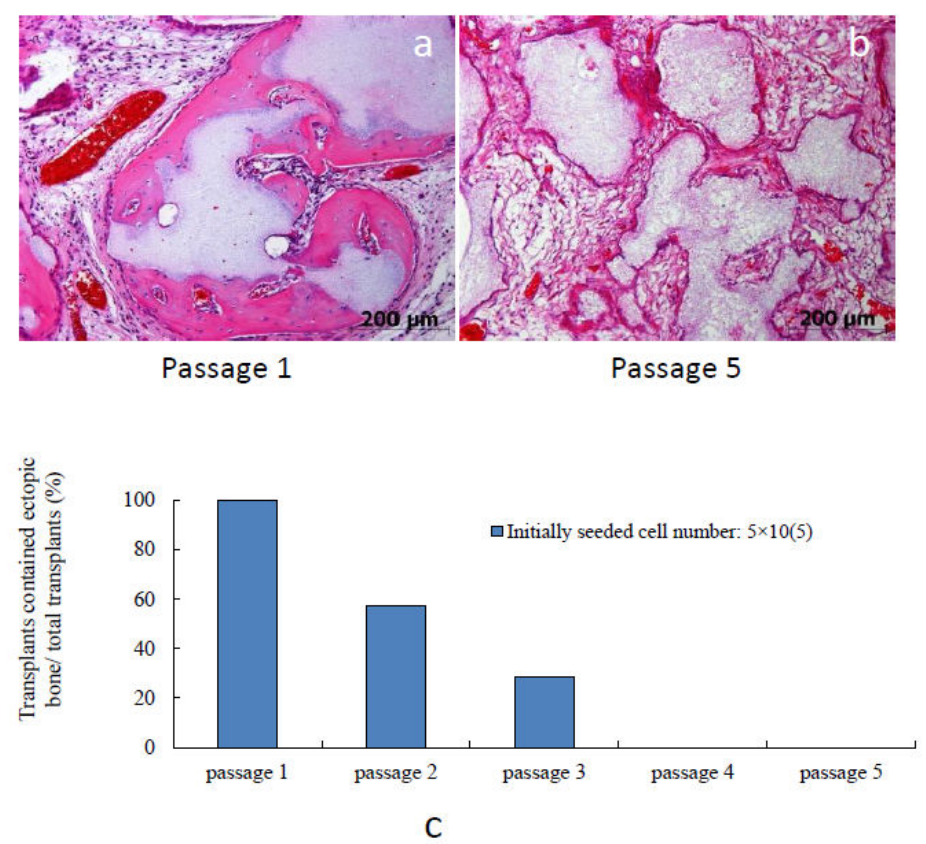

(Agata et al, 2010 and Kagami et al., 2014)

Figure 3. Effect of passage numbers on BMSC's ability for ectopic bone formation. Upper panels show ectopic bone formation on the back of nude mice with tissue-engineered bone using human BMSCs at passage 1 (a) and passage 5 (b). The success of ectopic bone formation quickly decrease after cell passage and no bone formation was observed after passage 4 (c). Note that the bone forming ability was quickly lost during passage. Adapted from Kagami et al., 2014 and modified from original figure in Agata et al., 2010. 
In terms of the safety of bone tissue engineering, BMSCs have been used clinically for more than ten years and no major side effect has been reported (Quatro et al., 2001). Accordingly, bone tissue engineering using BMSCs is considered relatively safe. However, genetic instability has been reported in mouse BMSCs, changes that might lead to carcinogenesis (reviewed by Prockop, 2009). Quest for the usage of more potent stem cells might be accompanied by a higher risk of genetic alteration, an issue that should be kept in mind in therapeutic applications of stem cells.

\subsection{Clinical bone tissue engineering in dentistry and maxillofacial surgery}

Tissue-engineered bone was first applied for long-bone defects (Quatro et al., 2001). In Quatro's study, autologous BMSCs were cultured with hydroxyapatite blocks and transplanted to the defective site. This study was the first to prove the clinical feasibility of bone tissue engineering.

In the field of dentistry, results from a first clinical study were reported in 2004. MSCs were mixed with platelet rich plasma as a scaffold and transplanted to the site of atrophic alveolar bone at the time of dental implant installation (Yamada et al., 2004). They reported that bone regeneration was observed in all cases. More recently, another clinical study using BMSCs was reported (Meijer et al., 2008). BMSCs were cultured and seeded on hydroxyapatite granules. Then, the cells were induced into osteogenic cells for one week and transplanted. In this study, the subjects included severe atrophy cases in which dental implant could not be installed at the time of cell transplantation (two steps approach). Bone formation was observed in three cases. However, in two cases where the atrophy was severe, newly formed bone was only observed in the area adjacent to the native bone, which might imply osteoconduction rather than bone regeneration by the transplanted cells. Accordingly, the efficacy of clinical alveolar bone tissue engineering for severe atrophy cases was not established in this study.

We have conducted a clinical study of bone tissue engineering for severe atrophy of alveolar bone. BMSCs were harvested from each patient's bone marrow, expanded in vitro, induced into osteogenic cells and transplanted together with $\beta$-TCP granules (Fig. 4). The results following two-and five-year observations proved that bone regeneration was successful and no side effects or related complications have been observed. On the other hand, one of the important findings through this clinical study was the presence of individual variations in cell growth, differentiation and levels of bone regeneration (Asahina et al., manuscript in preparation). This problem is not limited to bone tissue engineering and might be an important issue for the all therapies using autologous cells. Development of novel technologies to reduce individual variation is a current research target.

\subsection{Future prospect of bone tissue engineering in dentistry and maxillofacial surgery}

Currently, various techniques for bone regeneration/reconstruction are available, including microvascular-free flaps, autologous block bone transplantation, allogeneic or xenogeneic bone substitutes or purely artificial bone substitutes. Furthermore, recent development of additional strategies such as destruction osteogenesis, growth factor administration and tissue 


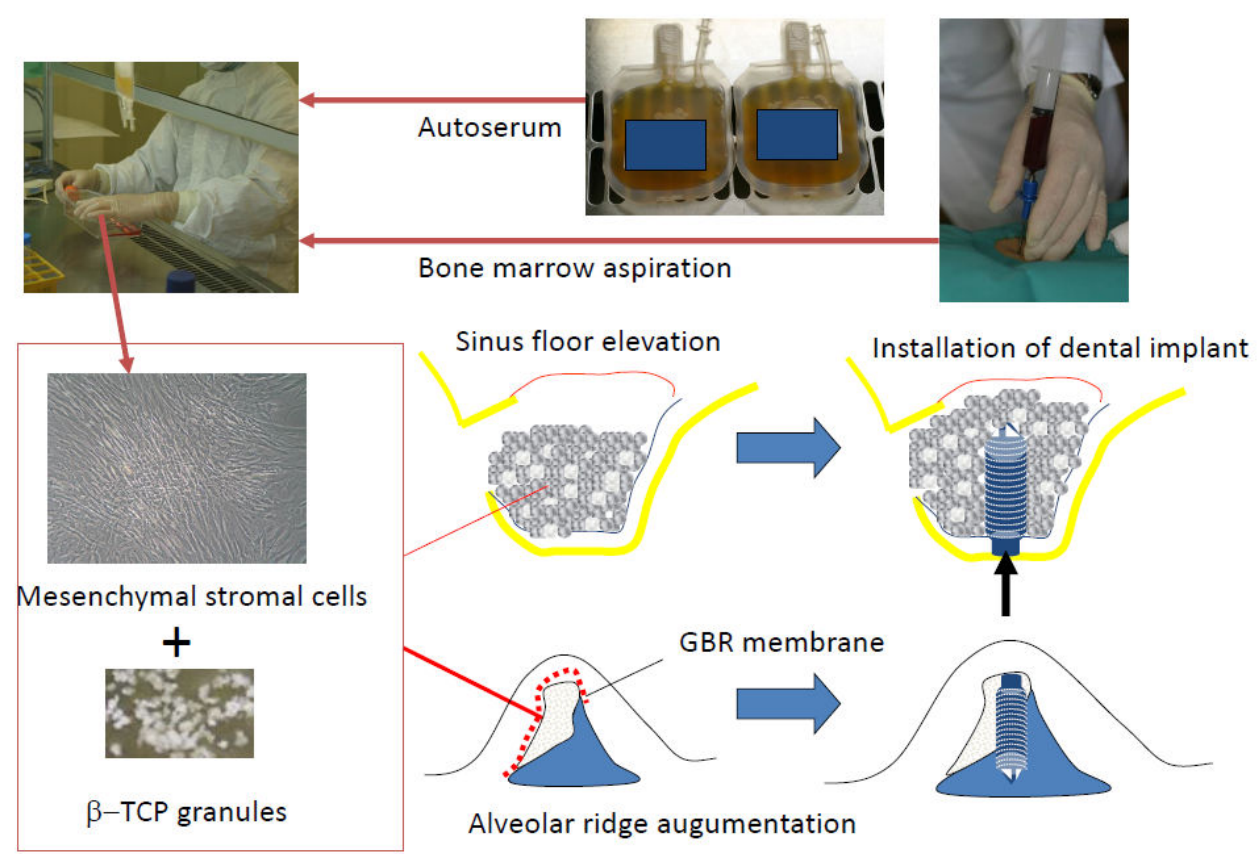

(Modified from Kagami et al., 2014)

Figure 4. The procedure for clinical study of alveolar bone regeneration at The Research Hospital, The Institute of Medical Science, The University of Tokyo. Modified from original figure in Kagami et al., 2014.

engineering will provide more options. Accordingly, the selection of an adequate technique for each case is of importance for practitioners.

When the tissue defect is relatively large and the condition of the recipient site is not optimal, the use of more invasive technique such as autologous bone grafting might be acceptable. However, future bone regeneration therapy will probably avoid surgical removal of healthy bone in favour of less invasive procedures. Bone tissue engineering is one of the most promising approaches and is expected to replace cases of autologous bone grafting. Currently, the best applications and most significant limitations of bone tissue engineering are not clear. Welldesigned clinical studies should be performed to answer these important questions, and these clinical trials will contribute to the wide acceptance of bone tissue engineering.

\section{Conclusion}

In the near future, a cell-based therapy will be accepted as a useful or even an essential treatment option for various diseases in dentistry and maxillofacial surgery. Based on previous and ongoing studies, radiation-damaged salivary glands and atrophic alveolar bone are the 
most realistic targets. Despite rapid progress in studies of cell-based therapies, this novel technology has yet to gain acceptance in ordinary practice. Since cell-based therapy is still expensive, determination of adequate treatment targets should be an important research goal to facilitate its widespread use. Furthermore, it is essential to reduce treatment costs without sacrificing safety. Development of automated cell culture systems and efficient safety tests are the key technologies to achieve this goal.

\section{Acknowledgements}

This work was supported in part by "Health Labour Sciences Research Grants" from the Ministry of Health, Labor and Welfare of Japan,"Grant-in-Aid for Scientific Research (B)", "Grant-in-Aid for challenging Exploratory Research" from Japan Society for the Promotion of Science (JSPS) and "Translational Research Network Program" from Ministry of Education, Culture, Sports, Science and Technology (MEXT) of Japan.

\section{Author details}

Yoshinori Sumita ${ }^{1}$, Izumi Asahina ${ }^{1}$, Simon D. Tran ${ }^{2}$, Hideki Agata ${ }^{1}$, Minoru Inoue $^{3,4}$, Arinobu Tojo ${ }^{3}$ and Hideaki Kagami ${ }^{3,4}$

1 Department of Regenerative Oral Surgery, Unit of Translational Medicine, Graduate School of Biomedical Sciences, Nagasaki University, Nagasaki, Japan

2 Laboratory of Craniofacial Tissue Engineering, Faculty of Dentistry, McGill University, Montreal, Quebec, Canada

3 Tissue Engineering Research Group, Division of Molecular Therapy, The Advanced Clinical Research Center, The Institute of Medical Science, The University of Tokyo, Tokyo, Japan

4 Department of Oral and Maxillofacial Surgery, Matsumoto Dental University, Shiojiri, Japan

\section{References}

[1] Agata, H., Asahina, I., Watanabe, N., Ishii, Y., Kubo, N., Ohshima, S., Yamazaki, M., Tojo, A. \&Kagami, H. (2010). Characteristic change and loss of in vivo osteogenic abilities of human bone marrow stromal cells during passage. Tissue Eng Part A, Vol.16, No.2,(October 2010), pp. 663-673, ISSN 1937-3341 (Print). 
[2] Atkinson, J.B., Mahoney, F.J., Schwartz, I.R. \& Hesch, J.A. (1959). Therapy of acute leukemia by whole-body irradiation and bone marrow transplantation from an identical normal twin. Blood. Vol. 14, No. 3, (March 1959), pp. 228-234, ISSN 0006-4971 (Print).

[3] Baum BJ, Tran SD. Synergy between genetic and tissue engineering - creating an artificial salivary gland. Periodontology2000. 2006;41:218-223

[4] Baum, B.J., Alevizos, I., Zheng, C., Cotrim, A.P., Liu, S., McCullagh, L., Goldsmith, C.M., Burbelo, P.D., Citrin, D.E., Mitchell, J.B., Nottingham, L.K., Rudy, S.F., Van Waes, C., Whatley, M.A., Brahim, J.S., Chiorini, J.A., Danielides, S., Turner, R.J., Patronas, N.J., Chen, C.C., Nikolov, N.P. \& Illei, G.G. (2012). Early responses to adenoviral-mediated transfer of the aquaporin-1 cDNA for radiation-induced salivary hypofunction. Proc Natl Acad Sci USA, Vol. 109, No. 47, (November 2012), pp. 19403-19407, ISSN: 0027-8424 (Print).

[5] Brittberg, M., Lindahl, A., Nilsson, A., Ohlsson, C., Isaksson, O. \& Peterson, L. (1994), Treatment of deep cartilage defects in the knee with autologous chondrocyte transplantation. N Engl J Med, Vol. 331, No. 14, (October 1994), pp. 889-895, ISSN 0021-9738 (Print).

[6] Caplan, A.I. (1991), Mesenchymal stem cells. J Orthop Res, (September 1991), Vol. 9, No. 5, pp. 641-650, ISSN:0736-0266 (Print).

[7] Friedenstein, A.J., Piatetzky-Chapiro, I.I. \& Petrakova, K.V. (1966), Osteogenesis in transplants of bone marrow cells. J Embryol Exp Morph, (December 1966), Vol.16, No. 3, pp. 381-390, ISSN:0022-0752 (Print).

[8] Friedenstein, A.J., Chailakhjan, R.K. \& Lalykina, K.S. (1970). The development of fibroblast colonies in monolayer cultures of guinea-pig bone marrow and spleen cells. Cell Tissue Kinet (October 1970), Vol. 3, No. 4, pp.393-403, ISSN:0008-8730 (Print).

[9] Friedenstein, A.J., Challakhyan, R.K., Gerasimov, U.V. (1987). Bone marrow osteogenic stem cells: in vitro cultivation and transplantation in diffusion chambers. Cell Tissue Kinet, (May 1987), Vol. 20, No. 3, pp. 263-272, ISSN:0008-8730 (Print).

[10] Gallico, G. G. 3rd, O'Connor, N. E., Compton, C. C., Kehinde, O. \& Green, H. (1984). Permanent Coverage of Large Burn Wounds with Autologous Cultured Human Epithelium. N Engl J Med, Vol. 311, No. 7, (August 1984), pp. 448-451, ISSN 0028-4793.

[11] Kagami, H., Wang, S. \& Hai, B. (2008). Restoring the function of salivary glands. Oral Dis. Vol. 14, No. 1, (January 2008), pp. 15-24, ISSN 1354-523X (Print).

[12] Kagami, H., Agata, H., Inoue, M., Asahina, I., Tojo, A., Yamashita, N. \& Imai, K. (2014). The Use of Bone Marrow Stromal Cells (Bone Marrow-Derived Multipotent Mesenchymal Stromal Cells) for Alveolar Bone Tissue Engineering: Basic Science to Clinical Translation. In press, (2014), ISSN 1937-3368 (Print).

[13] Khalili, S., Liu, Y., Sumita, Y., Maria, O.M., Blank, D., Key, S., Mezey, E. \& Tran, S.D. (2010). Bone marrow cells are a source of undifferentiated cells to prevent Sjogren's syn- 
drome and to preserve salivary glands function in the non-obese diabetic mice. Int J Biochem Cell Biol, (November 2010), Vol. 42, No. 11, pp. 1893-1899, ISSN:1357-2725 (Print).

[14] Khalili, S., Liu, Y., Kornete, M., Roescher, N., Kodama, S., Peterson, A., Piccirillo, C.A. \& Tran S.D. (2012). Mesenchymal stromal cells improve salivary function and reduce lymphocytic infiltrates in mice with Sjogren's-like disease. PLoS One, (June, 2012), Vol. 7, No. 6, pp.e38615, ISSN:1932-6203 (Electronic).

[15] Khalili, S., Faustman DL, Liu, Y., Sumita, Y., Blank, D., Peterson, A., Kodama, S. \& Tran, S.D. (2014). Treatment for salivary gland hypofunction at both initial and advanced stages of Sjogren-like disease: a comparative study of bone marrow therapy versus spleen cell therapy with a 1-year monitoring period. Cytotherapy, (March 2014), Vol. 6, No. 3, pp. 412-423, ISSN:1465-3249 (Print).

[16] Kodama, S., Kuhtreiber, W., Fujimura, S., Dale, E.A. \& Faustman, D.L. (2003). Islet regeneration during the reversal of autoimmune diabetes in NOD mice. Science, (November 2003), Vol. 302, No. 5648, pp. 1223-1227, ISSN:0036-8075 (Print).

[17] Kojima, T., Knemaru, S.-I., Hirano, S., Tateya, I., Ohno, S., Nakamura, T. \& Ito, J. (2011). Regeneration of radiation damaged salivary glands with adipose-derived stromal cells. Laryngoscope, (September 2011), Vol. 121, No. 9, pp. 1864-1869, ISSN:0023-852X (Print).

[18] Lim, J.Y., Yi, T., Choi, J.S., Jang, Y.H., Lee, S., Kim, H.J., Song, S.U. \& Kim, Y.M. (2013). Intraglandular transplantation of bone marrow-derived clonal mesenchymal stem cells for amelioration of post-irradiation salivary gland damage. Oral Oncol, (February 2013), Vol. 49, No. 2, pp. 136-143, ISSN:1368-8375 (Print).

[19] Lombaert, I.M., Brunsting, J.F., Wierenga, P.K., Faber,, H., Stokman, M.A., Kok, T., Visser, W.H., Kampinga, H.H., de Haan, G. \& Coppes R.P. (2008). Rescue of salivary gland function after stem cell transplantation in irradiated glands. PLoS One, (April 2008), Vol. 3, No. 4, pp. e2063, ISSN:1932-6203 (Electronic).

[20] Meijer, G.J., de Bruijn, J.D., Koole, R. \& van Blitterswijk, C.A. (2008). Cell based bone tissue engineering in jaw defects. Biomaterials, (July 2008), Vol. 29, No. 21, pp. 3053-3061, ISSN:0142-9612 (Print).

[21] McGovern, J.J. Jr., Russell, P.S., Atkins, L., Webster, E.W. (1956). Treatment of terminal leukemic relapse by total-body irradiation and intravenous infusion of stored autologous bone marrow obtained during remission. N Engl J Med. Vol. 260, No. 16, (April 1956), pp. 675-683, ISSN 0028-4793 (Print).

[22] Misuno, K., Tran, S.D., Khalili, S., Huang, J., Liu, Y. \& Hu, S. (2014). Quantitative analysis of protein and gene expression in salivary glands of Sjorgren's-like disease NOD mice treated by bone marrow soup. PLoS One, (January 2014), Vol. 9, No. 1, pp. e87158, ISSN: 1932-6203 (Electronic).

[23] Ogawa, M., Oshima, M., Imamura, A., Sekine, Y., Ishida, K., Yamashita, K., Nakajima, K., Hirayama, M., Tachikawa, T. \& Tsuji, T. (2013). Functional salivary gland regen- 
eration by transplantation of a bioengineered organ germ. Nat Commun, Vol. 4, pp. 2498, ISSN:2041-1723 (Electronic).

[24] Pittenger, M.F., Mackay, A.M., Beck, S.C., Jaiswal, R.K., Douglas, R., Mosca, J.D., Moorman, M.A., Simonetti, D.W., Craig, S. \& Marshak, D.R. (1999). Multilineage potential of adult human mesenchymal stem cells. Science (April 1999), Vol. 284, No. 5411, pp. 143-147, ISSN:0036-8075 (Print).

[25] Prockop DJ. (2009). Repair of tissues by adult stem/progenitor cells (MSCs): controversies, myths, and changing paradigms. Mol Ther, (June 2009), Vol. 17, No. 6, pp. 939-946, ISSN:1525-0016 (Print).

[26] Quatro, R., Mastrogiacomo, M. \& Cancedda, R. (2001). Repair of large bone defects with the use of autologous bone marrow stromal cells. N Engl J Med (February 2001), Vol. 344, No. 5, pp. 385-386, ISSN:0028-4793 (Print).

[27] Shapiro, A.M., Lakey, J.R., Ryan, E.A., Korbutt, G.S., Toth, E., Warnock, G.L., Kneteman, N.M. \& Rajotte, R.V. (2000). Islet transplantation in seven patients with type 1 diabetes mellitus using a glucocorticoid-free immunosuppressive regimen. N Engl J Med. Vol. 343, No. 4, (July 2000), pp. 230-238, ISSN 0028-4793.

[28] Sugito, T., Kagami, H., Hata, K., Nishiguchi, H. \& Ueda, M. (2004). Transplantation of cultured salivary gland cells into an atrophic salivary gland. Cell Transplant, Vol. 13, No. 6, pp. 691-699, ISSN:0963-6897 (Print).

[29] Sumita, Y., Liu, Y., Khalili, S., Maria, O.M., Xia, D., Key, S., Cotrim, A.P., Mezey, E. \& Tran, S.D. (2011). Bone marrow-derived cells rescue salivary gland function in mice with head and neck irradiation. Int J Biochem Cell Biol, (January 2011), Vol. 43, No. 1, pp. 80-87, ISSN:1357-2725 (Print).

[30] Thomas, E.D., Lochte, H.L. Jr., Cannon, J.H., Sahler, O.D., Ferrebee, J.W. (1959). Supralethal whole body irradiation and isologous marrow transplantation in man. J Clin Invest. (October 1959), Vol. 38, No. 10 (Pt 1-2), pp. 1709-1716, ISSN 0021-9738 (Print).

[31] Tran, S.D., Wang, J., Bandyopadhyay, B.C., Redman, R.S., Dutra, A., Pak, E., Swaim, W.D., Gerstenhaber, J.A., Bryant, J.M., Zheng, C., Goldsmith, C.M., Kok, M.R., Wellner, R.B. \& Baum, B.J. (2005). Primary culture of polarized human salivary epithelial cells for use in developing an artificial salivary gland. Tissue Eng, (January-February 2005), Vol. 11, No. 1-2, pp. 172-181, ISSN:1076-3279 (Print).

[32] Tran, S.D., Kodama, S., Lodde, B.M., Szalayova, I., Key, S., Khalili, S., Faustman, D.L. \& Mezey, E. (2007). Reversal of Sjogren's-like syndrome in non-obese diabetic mice. Ann Rheum Dis, (June 2007), Vol. 66, No. 6, pp. 812-814, ISSN:0003-4967 (Print).

[33] Tran, S.D., Sumita, Y. \& Khalili, S. (2011). Bone marrow-derived cells: A potential approach for the treatment of xerostomia. Int J Biochem Cell Biol. (October 2010), Vol. 43, No. 1, pp. 5-9, ISSN 1357-2725 (Print).

[34] Tran, S.D., Redman, R.S., Barrett, A.J., Pavletic, S.Z., Key, S., Liu, Y., Carpenter, A., Nguyen, H.M., Sumita, Y., Baum, B.J., Pillemer, S.R. \& Mezey, E. (2011). Microchimer- 
ism in salivary glands after blood- and marrow-derived stem cell transplantation. Biol Blood Marrow Transplant, (March, 2011), Vol. 17, No. 3, pp. 429-433, ISSN:1083-8791 (Print).

[35] Tran, S.D., Liu, Y., Xia, D., Maria, O.M., Khalili, S., Wang, R.W., Quan, V.H., Hu, S. \& Seuntjens, J. (2013). Paracrine effects of bone marrow soup restore organ function, regeneration, and repair in salivary glands damaged by irradiation. PLoS One, (April 2013), Vol. 8, No 4, pp. e61632, ISSN:1932-6203 (Electronic).

[36] Yamada, Y., Ueda, M., Hibi, H. \& Nagasaka, T. (2004). Translational research for injectable tissue-engineered bone regeneration using mesenchymal stem cells and platelet-rich plasma: from basic research to clinical case study. Cell Transplant, Vol. 13, No. 4, pp. 343-355, ISSN:0963-6897 (Print).

[37] Yoshikawa, T., Ohgushi, H. \& Tamai, S. (1996). Immediate bone forming capability of prefabricated osteogenic hydroxyapatite. J Biomed Mater Res (November 1996), Vol. 32, No. 3, pp. 481-492, ISSN:0021-9304 (Print).

[38] Xu, J., Xu, J., Wang, D., Liu, D., Fan, Z., Zhang, H., Liu, O., Ding, G., Gao, R., Zhang, C., Ding, Y., Bromberg, J.S., Chen, W., Sun, L. \& Wang, S. (2012). Allogeneic mesenchymal stem cell treatment alleviates experimental and clinical Sjogren's syndrome. Blood. (October 2011), Vol. 120, No. 15, pp. 3142-3151, ISSN:0006-4971 (Print). 